\title{
Benefits of local structural protection to mitigate torrent-related hazards
}

\author{
M. Holub \& S. Fuchs \\ Institute of Mountain Risk Engineering, \\ University of Natural Resources and Applied Life Sciences, Vienna, \\ Austria
}

\begin{abstract}
The increasing land-use activities in European mountain regions have led to a considerable threat of natural hazards such as flash floods and debris flows in areas used for settlement purposes and economic activities. To mitigate associated losses, traditional protective measures, including check dams and retention basins, were commonly implemented by public authorities. However, due to the scarceness of public funds, efficient protection alternatives have to be developed to reduce future expenditures. Supplementing the concept of integral risk management, this efficiency can be obtained by local structural protection, reducing the vulnerability of buildings and infrastructure facilities considerably. However, data related to the effects of local structural protection measures to reduce losses has not been quantified satisfyingly so far, and the associated decrease in vulnerability has hardly been measured until now. In this paper, results of a comparative standardised cost benefit analysis are presented. Different mitigation strategies were assessed and the benefit of local structural measures was quantified. The results suggest that local structural measures reduce the vulnerability of buildings towards natural hazards considerably, and that they therefore should be considered as either additional or even alternative mitigation measures.
\end{abstract}

Keywords: integral risk management, vulnerability, cost-benefit analysis, local structural measures, natural hazards. 


\section{Introduction}

In the second half of the $20^{\text {th }}$ century a noticeable socio-economic development took place in Alpine regions, which resulted in a significant aggregation of settlements and infrastructure facilities, and consequently in an accumulation in tangible assets. These areas are increasingly and repeatedly threatened by natural hazards such as flash floods, debris flows and avalanches, since safe regions suitable for development are relatively sparse in mountain regions [1]. As a result, an increase in losses due to hazard processes had been observed in recent years world-wide as well as on a European level [2], even though in Alpine areas losses from avalanches and torrent processes appeared to decrease [3, 4].

Dealing with natural hazards has a long tradition in the Alps. During past centuries, areas potentially endangered were predominantly used for extensive agricultural purposes to avoid danger. Since the end of the $19^{\text {th }}$ century, a change in these patterns of utilisation is traceable, the first authorities for the protection of natural hazards were founded, e.g. in Austria in 1884 [5]. For more than half a century technical mitigation measures were developed and put in place. These active measures, representing the human reaction to hazard processes, appeared to be the appropriate way to cope with this challenge. Conventional structural mitigation, such as checkdams, torrential barriers and retention facilities, were supplemented by watershed management, and above all, forestal measures and soil-bioengineering. Since the 1960s, these conventional mitigation measures were complemented by passive protection concepts, and hazard maps were introduced aiming to reduce an exposure to hazards. The need for hazard mapping was regulated in the Austrian law related to forests in 1975 [6] and an associated decree in 1976 [7].

However, neither conventional measures, which influence both the intensity and the frequency of events, nor passive mitigation concepts can guarantee reliability and complete safety [8]. Thus, a residual risk of damage to buildings and infrastructure as well as of harm to people remains [9, 10]. Furthermore, technical mitigation concepts are cost-intensive in construction and maintenance, which is an increasing problem for public authorities as a major fund provider due to the overall budget constraints.

Local structural protection measures, which are implemented directly at or adjacent to endangered objects, might therefore be a valuable and serious alternative with respect to the concept of integral risk management [11]. However, the effect of local structural protection in reducing susceptibility of values at risk has not been quantified satisfyingly so far [12], even if the positive effect in reducing vulnerability seems to be obvious. At first it will be necessary to compare the advantages and disadvantages of conventional mitigation measures and local structural protection, an above all the cost-efficiency. In this paper this is done for a small catchment in the Eastern Alps, Austria, with respect to flash floods with fluvial bed load transport in order to provide data related to possible mitigation concepts for the responsible political decision makers. 


\section{Method}

Since mitigation measures have characteristics of public goods, above all nonexcludability and non-rivalry, the private sector does not supply them in a sufficiently great enough quantity given the potential economic benefits to society. Therefore, the supply must take place via the public sector. As a result of the increasingly limited financial resources of the public sector there is a need for an efficient and sustainable policy of public expenditures for protection against natural hazards [13]. Consequently, the costs and benefits of mitigation measures will be increasingly determined to allow for a comparison of the costeffectiveness of different measures and an evaluation of the economic efficiency of mitigation strategies. Mitigation measures are considered economically beneficial if the utility produced by them exceeds or is equal to the associated costs. From an economic point of view, mitigation measures should not only be implemented with minimised costs (cost-efficiency), rather they should be provided on a socially optimal scale (allocative efficiency; [14]). In order to provide the optimal supply of protection measures, the public sector will need, among other information, evaluations of the costs and benefits of mitigation approaches. Three alternative assessment methods are available for decision making, (i) cost-effectiveness analysis, (ii) cost-efficiency analysis, and (iii) costbenefit analysis. Even if all three methods can be applied as decision tool for public and private projects, the latter is the only method to directly assess both, costs and benefits in monetary terms [15]. Thus, the cost-benefit analysis seems to be an appropriate instrument to study and compare advantages and disadvantages of different mitigation scenarios.

In this paper, a standardised method for cost-benefit analysis developed by the Institute of Mountain Risk Engineering, University of Natural Resources and Applied Life Sciences in collaboration with the Austrian Federal Ministry of Agriculture, Forestry, Environment and Water Management was used to assess the cost-efficiency of different mitigation concepts in a small alpine catchment $[16,17]$.

\subsection{Test site}

The rural Auenbach test site is situated in a sub-catchment of the Lavant valley, located in the eastern part of Carinthia, Austria, near the border to Slovenia (figure 1). The southeast exposed valley of the test site shows a total length of $12.5 \mathrm{~km}$ and a total difference in elevation of $890 \mathrm{~m}$. A district of the village of Prebl is situated along the valley bottom, with a total of 67 buildings, 54 of which in the categories of residential buildings and farm buildings. Due to the steep topography, the slopes are susceptible to mass movement processes, in particular shallow landslides. Within the last decades the test site was affected by periodic flood events. Impacts originating from static or dynamic flood as well as from extraordinary surface runoff, accompanied by transport of solids, endanger the stability of the buildings (see figure 2). The major processes at the valley bottom include the possible intrusion of water and solids through the building 
openings causing damage to the interior of the buildings. These flood events resulted in conventional mitigation activities in the test site; measures such as ripraps and bank revetments were built for almost 60 years.

In 2005, a re-activated landslide in the upper part of the catchment resulted in intensive discussion about the capacities of the current mitigation strategies. In particular, flash floods resulting from a possible blocking of the river due to the sliding mass and a subsequent outbreak were addressed. As a result, the Austrian Torrent and Avalanche Control Service planned to implement a new torrential barrier to avert losses due to flash floods with fluvial bed load transport in the lower parts of the catchment.

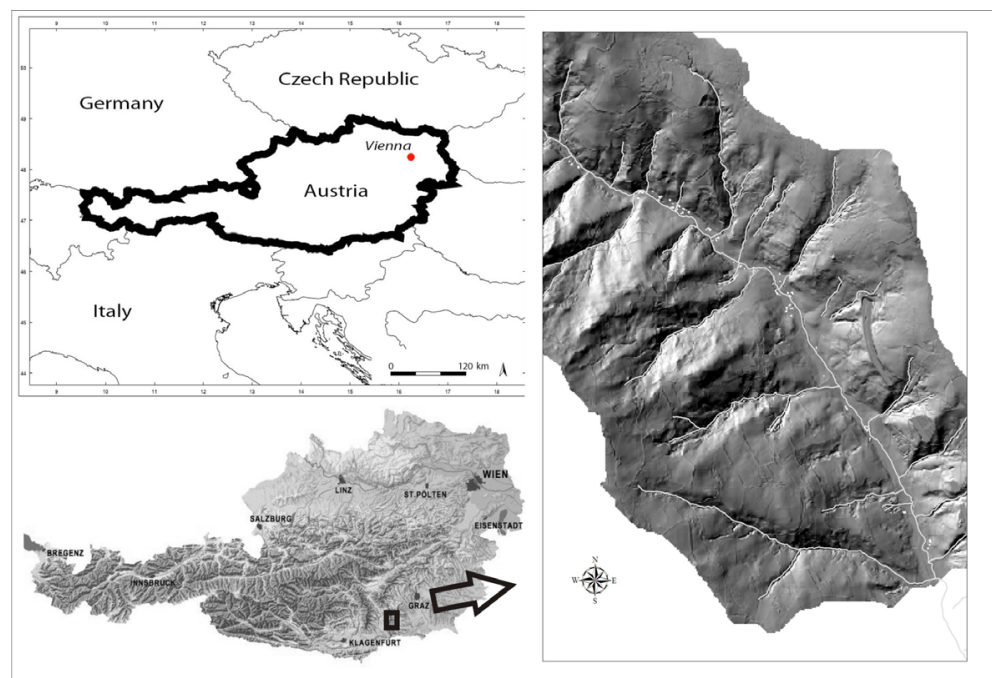

Figure 1: $\quad$ Location of the Auenbach test site (Carinthia, Austria).

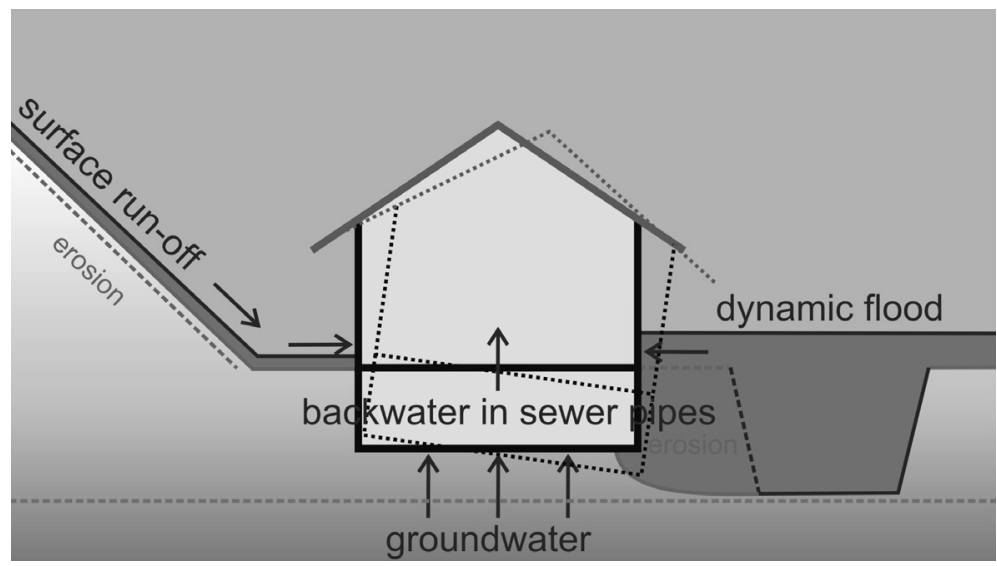

Figure 2: $\quad$ Damage patterns due to static and dynamic flooding. 


\subsection{Risk analysis}

By means of hydrologic calculations and 2-dimensional hydraulic numerical modelling, the design event with a return period of 150 years was calculated for the test site. Based on these results and according to the legal regulations of hazard zoning in Austria, yellow and red hazard zones were determined. The red hazard zone is defined by the energy line $>1.5 \mathrm{~m}$ in height and torrential depositions $>0.7 \mathrm{~m}$. The yellow hazard zone is defined by the energy line $<1.5 \mathrm{~m}$ and torrential depositions $<0.7 \mathrm{~m}$, respectively $[7,11]$.

The elements at risk were analysed with respect to their spatial location and extension using GIS. The category, size and shape of the buildings was recorded from digital datasets of the communal administration and updated during a field study. A total of 49 buildings are affected by possible flash flood events, seven of which are located in the red hazard zone. In the yellow hazard zone, 42 buildings are located (see table $1 ; \mathrm{HZ}=$ hazard zone; $\mathrm{SFH}=$ single family house; $\mathrm{MFB}=$ main farming building; $\mathrm{AFB}=$ adjoining farming building; $\mathrm{STB}=$ stable; $\mathrm{GAR}=$ garage) .

The evaluation of the elements at risk was carried out according to the federal guidelines [16]. Thus, a vulnerability factor of 0.1 and 0.3 was applied in the yellow and red hazard zone. The economic valuation of the exposed buildings was carried out [17]. Hence, data on the volume of the buildings were sampled and average prices of reconstruction per cubic metre according to the type and function of individual buildings were assigned [18].

Table 1: $\quad$ Number of buildings according to category and hazard zone.

\begin{tabular}{|c|r|r|r|r|r|r|}
\hline HZ & \multicolumn{1}{|c|}{ SFH } & \multicolumn{1}{|c|}{ MFB } & \multicolumn{1}{|c|}{ AFB } & \multicolumn{1}{|c|}{ STB } & \multicolumn{1}{c|}{ GAR } & \multicolumn{1}{c|}{ TOTAL } \\
\hline $\begin{array}{c}\text { Yellow } \\
0.7 \mathrm{~m}\end{array}$ & 17 & 1 & 7 & 2 & 7 & 34 \\
\hline $\begin{array}{c}\text { Yellow }> \\
0.7 \mathrm{~m}\end{array}$ & 3 & 1 & 2 & 0 & 2 & 8 \\
\hline $\begin{array}{c}\text { Red } \\
>1.5 \mathrm{~m}\end{array}$ & 0 & 0 & 2 & 2 & 3 & 7 \\
\hline TOTAL & 20 & 2 & 11 & 4 & 12 & 49 \\
\hline
\end{tabular}

\subsection{Mitigation concepts}

Two fundamentally different concepts of mitigation were compared in this study, (i) a concept of conventional mitigation based on the implementation of torrential structures and (ii) a concept of local structural protection for buildings located in the endangered areas.

The conventional concept was based on structural measures such as retaining and filtering barriers as well as retention basins in the upper part of the catchment. According to this mitigation concept, buildings within the red and yellow zone would be protected from major impacts associated with the assumed design event. Additionally, damage to infrastructure facilities such as the road network and the sewerage system, and agricultural and silvicultural areas could be averted. 
The concept of local structural protection was based on the catalogue of local structural measures to protect buildings against floods [11]. Measures such as enhanced constructions and sealed openings were assumed to efficiently protect buildings from hazard impacts up to a height of approximately $0.7 \mathrm{~m}$ (figure 3 and 4). Consequently, they are not suitable to protect buildings in the red hazard zone. Furthermore, since local structural protection is only appropriate for the protection of buildings, damage to adjacent or adjoining infrastructure will not be reduced.

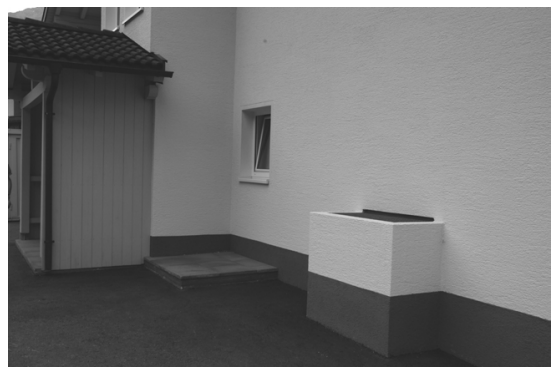

Figure 3: Enhancement (raising) of light wells above flood level.

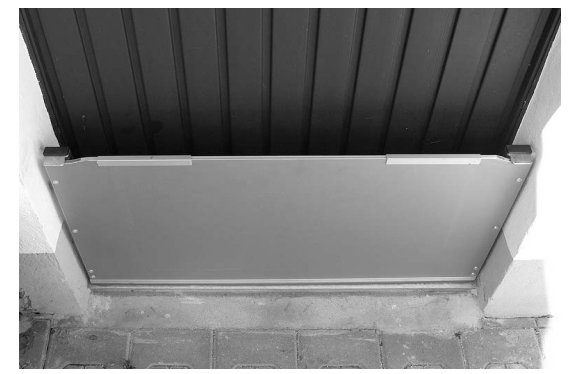

Figure 4:

Sealing of openings by half-sided plates by magnet technique (WHS, 2007).

\subsection{Cost-benefit analysis}

A standardised method of cost-benefit analysis was applied to obtain the costefficiency of planned mitigation measures [16]. During the cost-benefit analysis, i) absolute cost efficiency and ii) relative cost efficiency considering several alternatives were assessed. Thus, costs and benefits were monetarily quantified. Since costs and benefits occur during different time intervals they were discounted using the interest rate of $3.5 \%$ derived from the average rate of interest of long-lasting federal bonds. Applying empirically derived coefficients for the major transport process, the event magnitude, the defined design event and the resulting vulnerability of elements at risk, the cost-benefit analysis was adjusted to meet the protection targets.

\subsubsection{Costs}

For the conventional mitigation concept, the cost estimate resulted in a project sum of approximately $€ 1.3$ million. Taking into account maintenance and discounting to the present-day net value, costs summed up to $€ 1.36$ million.

Calculating the total costs for local structural measures, building properties (cellar, hillside situation, garage possibly integrated in the building) were found to have a major influence on the calculation. Garages detached to buildings, buildings in the red hazard zone and buildings in the yellow hazard zone where the deposition height and/or the flow depth exceeded $0.7 \mathrm{~m}$ were not taken into 
account since they cannot be protected by local structural measures. In table 2 , the input data used for the estimation of costs is shown. The total costs for necessary local structural measures resulted in approximately $€ 270,000$.

Table 2: Overview of building properties and corresponding costs per building for the implementation of local structural protection measures (prices include 20\% tax and assembly).

\begin{tabular}{|l|c|c|c|c|c|c|}
\hline $\begin{array}{c}\text { Building } \\
\text { properties }\end{array}$ & $\begin{array}{c}\text { Entrance door } \\
(€ 1,200) \\
\text { half sided } \\
\text { sealing plate } \\
\text { width } 1.0 \mathrm{~m} \\
\text { height } 1.0 \mathrm{~m}\end{array}$ & $\begin{array}{c}\text { Terrace door } \\
(€ 1,200) \\
\text { half sided } \\
\text { sealing plate } \\
\text { width } 1.0 \mathrm{~m} \\
\text { height } 1.0 \mathrm{~m}\end{array}$ & $\begin{array}{c}\text { Light wells } \\
(€ 1,000) \\
\text { enhancement } \\
\text { (raising) } \\
\text { height } 1.0 \mathrm{~m}\end{array}$ & $\begin{array}{c}\text { Garage door } \\
(€ 3,000) \\
\text { half sided } \\
\text { sealing plate } \\
\text { width } 2.5 \mathrm{~m} \\
\text { height } 1.0 \mathrm{~m}\end{array}$ & $\begin{array}{c}\text { Entrance door } \\
(€ 1,800) \\
\text { half sided } \\
\text { sealing plate } \\
\text { width } 1.5 \mathrm{~m} \\
\text { height } 1.0 \mathrm{~m}\end{array}$ & Costs $[€]$ \\
\hline with cellar & 1 & 1 & 6 & 0 & 0 & 8,400 \\
\hline without cellar & 1 & 1 & 0 & 0 & 0 & 2,400 \\
\hline $\begin{array}{l}\text { hillside situation, } \\
\text { integrated garage }\end{array}$ & 1 & 0 & 0 & 1 & 0 & 4,200 \\
\hline stable without cellar & 2 & & & & 1 & 4,200 \\
\hline
\end{tabular}

\subsubsection{Benefits}

The benefit was defined as prevented damage to buildings in the test site. Therefore, elements at risk had been evaluated according to the requirements of the cost-benefit analysis taking the data from the risk analysis. Since local structural measures prevent direct damage to buildings, potential additional benefits such as the protection of infrastructure facilities, agricultural and silvicultural areas were not taken into account during the analysis.

\subsubsection{Mitigation scenarios}

Three scenarios had been defined according to the requirements of the responsible decision maker, (i) conventional mitigation measures aiming to avoid future design events, (ii) local structural measures neglecting that they could not fully avoid losses due to design events, and (iii) local structural measures taking into account these possible losses on the cost side of the mitigation concept.

a. Scenario 1: CMM

Conventional mitigation measures are implemented; protection for all elements at risk in red and yellow hazard zones (HZ).

b. Scenario 2: LSM

Local structural protection measures; protection for objects inside the yellow hazard zone to a deposition height and/or flow depth $<0.7 \mathrm{~m}$ (yellow HZ); no protection for detached garages.

c. Scenario 3: LSM+

Local structural protection measures; additional costs (equals a reduction of benefit) due to arising losses from those buildings that are not equipped with local structural protection in red and yellow hazard zones; protection for objects inside the yellow hazard zone to a deposition height and/or flow depth $<0.7 \mathrm{~m}$ (yellow HZ); no protection for detached garages.

In table 3 the input data used during the cost-benefit analysis and the calculation of the benefit-cost-ratio are shown. 
Table 3: $\quad$ Input data used for the cost-benefit analysis.

\begin{tabular}{|l|r|r|r|}
\cline { 2 - 4 } \multicolumn{1}{c|}{} & CMM & LSM & LSM+ \\
\hline Event factor [1] & 2 & 2 & 2 \\
\hline Process factor [1] & 1 & 1 & 1 \\
\hline Damage factor in yellow HZ [1] & 0.1 & 0.1 & 0.1 \\
\hline Damage factor in red HZ [1] & 0.3 & 0.3 & 0.3 \\
\hline Protected buildings in yellow HZ $<0.7$ m [1] & 33 & 27 (no garages) & 27 (no garages) \\
\hline Protected buildings in yellow HZ>0.7 m [1] & 9 & 0 & 0 \\
\hline Protected buildings in red HZ [1] & 7 & 0 & 0 \\
\hline Intangible benefit [1] & 1.1 & 1.1 & 1.1 \\
\hline Examination time period [a] & 80 & 80 & 80 \\
\hline Interest rate [\%] & 3.5 & 3.5 & 3.5 \\
\hline Total costs, rounded [€] & $1,300,000$ & 220,000 & 360,000 \\
\hline
\end{tabular}

Event factor 2: large, medium and small events are taken into account

Process factor 1: fluvial bedload transport with a magnitude up to the design event

Table 4: $\quad$ Results from the cost-benefit analysis.

\begin{tabular}{|c|c|c|c|}
\hline & CMM & LSM & LSM+ \\
\hline Protected buildings in yellow $\mathrm{HZ}<0.7 \mathrm{~m}$ [1] & 33 & 27 (no garages) & 27 (no garages) \\
\hline Protected buildings in yellow $\mathrm{HZ}>0.7 \mathrm{~m}$ [1] & 9 & 0 & 0 \\
\hline Protected buildings in red $\mathrm{HZ}$ [1] & 7 & 0 & 0 \\
\hline Tangible benefit, rounded [€] & 667,000 & 523,000 & 380,000 \\
\hline Intangible benefit, rounded [€] & 67,000 & 52,000 & 38,000 \\
\hline Total benefit without coefficients, rounded [€] & 734,000 & 576,000 & 417,000 \\
\hline Total benefit with coefficients, rounded [€] & $1,468,000$ & $1,151,000$ & 835,000 \\
\hline Total costs without discounting, rounded [€] & $1,612,000$ & 273,000 & 273,000 \\
\hline Total costs with discounting, rounded [€] & $1,360,000$ & 230,000 & 230,000 \\
\hline Capital value, rounded [€] & $-870,000$ & 155,000 & 49,000 \\
\hline Ratio benefit-costs [1] & 0.36 & 1.67 & 1.21 \\
\hline
\end{tabular}

\section{Results}

The results of the cost-benefit analysis are presented in table 4. In general, the mitigation concepts using local structural measures (LSM and LSM+) offer a better benefit-cost-ratio of 1.67 and 1.21 than the concept based on conventional measures (CMM; 0.36).

For scenario CMM, the total benefits to be created amounted to $€ 1,468$ million. Even if in scenario CMM the number of protected buildings was higher (49) than in scenarios LSM and LSM+ (27), the benefit-cost ratio was < 1 due to the relatively high costs associated with the planned conventional mitigation measures (discounted: $€ 1.36$ million). As a consequence, the net present value became negative, and amounted to $€-870,000$. However, it has to be taken into account that scenario CMM was the only concept providing protection for all buildings in both, the red and the yellow hazard zone. Furthermore, though beyond the boundary of the studied system, additional benefits might be created by this concept since it also offers protection to values at risk located further downstream adjacent to the receiving stream.

For scenario LSM, the total benefits to be created amounted to $€ 1,151$ million, and the total costs to $€ 230,000$. Thus, scenario LSM showed the best benefit-cost ratio of 1.67 , even if local structural protection would only be provided up to flow depths and deposition heights of $0.7 \mathrm{~m}$, and therefore no buildings situated in areas exceeding this value were protected. Consequently, it 
has been taken into account that all other values at risk (detached garages, buildings inside the red hazard zone and buildings in the yellow hazard zone where the deposition height and/or the flow depth exceeded $0.7 \mathrm{~m}$ ) cannot be satisfyingly sheltered from damage.

As a result, losses might occur, which had been considered in the set of calculation for scenario LSM +. Consequently, the possible benefit was reduced by necessary reconstruction costs for buildings located in areas with flow depths and deposition heights $>0.7 \mathrm{~m}$. Thus, the benefits were reduced to $€ 835,000$ while costs of $€ 230,000$ occurred. As a result, the benefit-cost ratio was reduced to 1.21 ; however, this scenario was still cost-efficient.

To conclude, if decisions regarding mitigation concepts in the test site were only based on cost-benefit analyses, scenario LSM+ (taking into account possible losses at buildings that are not protected by local structural measures) showed the best benefit-cost ratio, while the conventional mitigation concept was the least efficient.

\section{Conclusion and discussion}

Recent studies related to torrential hazards in Austria suggested a considerable decrease in vulnerability, if local structural protection is implemented [12]. However, possible associated risk-minimising effects of local structural measures were not quantified satisfyingly so far. To close this gap, and provide insight in these effects, a standardised cost-benefit analysis was applied for an Alpine catchment, using an ex-ante perspective. Considerable different benefitcost ratios were obtained, depending on (i) a relatively high amount of expenditures necessary for conventional mitigation and (ii) a relatively small amount of values at risk to be protected. Mitigation concepts based on local structural measures showed benefit-cost ratios $>1$, even if the protective effects of local structural measures are limited to deposition heights of approximately $0.7 \mathrm{~m}$. Thus, cost-benefit analyses are very case-sensitive, and results are hardly transferable to other regions. The assumptions made in this study were conservative, above all with respect to the boundaries of the system. Whether or not a test site is considered as a closed system or as an open system in terms of a sub-catchment within a river network, the concept of implementing local structural protection measures will result in different benefit-cost ratios.

However, local structural protection is a serious and promising approach in mitigating natural hazards. Comparing costs of local structural protection with those of conventional mitigation measures, a significant potential for saving future public expenditures exists since such measures usually have to be funded and implemented by the private households. To increase individual responsibility for mitigation, and to achieve a broader acceptance for such measures, information and possibly participation of affected people seems to be essential, since in general people have a high confidence in conventional technical mitigation concepts. Apart from an enhanced enforceability of necessary legal regulations such as building codes, as a side effect, such information campaigns will result in an increased risk awareness of people concerned. Accordingly, 
individual responsibility will be strengthened, and the society will be able to alternatively use (increasingly scarce) public funds in a more cost-efficient way.

Apart from engineering foci presented above, it has to be emphasised that local structural measures generally fit better in the landscape than traditional mitigation measures. Even if a quantification of this effect is outstanding, measures protecting individual objects usually consist of smaller structures, which could be integrated harmonically into the appearance of a building.

Considering all these aspects provides a possible ability for decision makers to take into account advantages and disadvantages of conventional and local structural protection measures. Consequently, the concept of local protection should be embedded within the framework of integral risk management strategies. However, the decision will often be a political one, as recent years have shown. Hence, further studies have to be carried out in order to assess the effects and consequences of local structural protection for a future enhancement of risk-minimising efforts with respect to buildings and infrastructure facilities.

\section{References}

[1] Fuchs, S. \& Keiler, M., Variability of natural hazard risk in the European Alps - Evidence from damage potential exposed to snow avalanches, ed. Pinkowski, J., Disaster management handbook, London, pp. 264-275, 2008.

[2] Munich Re, Topics Geo, Natural catastrophes 2006 - Analyses, assessments, positions, München, 2007.

[3] Fuchs, S. \& Bründl, M., Damage potential and losses resulting from snow avalanches in settlements in the Canton of Grisons, Switzerland, Natural Hazards, 34, pp. 53-69, 2005.

[4] Oberndorfer, S., Fuchs, S., Rickenmann, D. \& Andrecs, P., Vulnerabilitätsanalyse und monetäre Schadensbewertung von Wildbachereignissen in Österreich. Wien, 2007.

[5] Länger, E., Geschichtliche Entwicklung der Gefahrenzonenplanung in Österreich, Wildbach- und Lawinenverbau, 152, pp. 13-24, 2005.

[6] Republik Österreich, Forstgesetz 1975, Bundesgesetzblatt 440/1975, in der Fassung BGB1. I 83/2004, 2003.

[7] Republik Österreich, Verordnung des Bundesministers für Land- und Forstwirtschaft vom 30. Juli 1976 über die Gefahrenzonenpläne, BGB1. 436/1976, Wien, 1976.

[8] Schmid, F., Gefahrenzonenplan - Fluch oder Segen? Wildbach- und Lawinenverbau, 152, pp. 93-104, 2005.

[9] Fell, R., Landslide risk assessment and acceptable risk, Canadian Geotechnical Journal, 31, pp. 261-272, 1994.

[10] BMLFUW, Flood protection in Austria, Bundesministerium für Land- und Forstwirtschaft, Umwelt und Wasserwirtschaft, Wien, 2006.

[11] Holub, M. \& Hübl, J., Local protection against mountain hazards - State of the art and future needs, Natural Hazards and Earth System Sciences, 8, in press. 
[12] Fuchs, S., Heiss, K. \& Hübl, J., Towards an empirical vulnerability function for use in debris flow risk assessment, Natural Hazards and Earth System Sciences, 7, pp. 495-506, 2007.

[13] Fuchs, S. \& McAlpin, M.C., The net benefit of public expenditures on avalanche defence structures in the municipality of Davos, Switzerland, Natural Hazards and Earth System Sciences, 5, pp. 319-330, 2005.

[14] Weck-Hannemann, H., Efficiency of protection measures, ed. Ammann W., Dannenmann, S. \& Vuillet, L., Risk21 - Coping with risks due to natural hazards in the $21^{\text {st }}$ century, London, pp. 147-154, 2006.

[15] Thöni, M., Was sind Schutzmaßnahmen wert? Wildbach- und Lawinenverbau, 153, 67-73, 2006.

[16] BMLFUW, Richtlinien für die Wirtschaftlichkeitsuntersuchung und Priorisierung von Maßnahmen der Wildbach- und Lawinenverbauung gemäß $§ 3$ Abs. 2 Z 3 Wasserbautenförderungsgesetz, Bundesministerium für Land- und Forstwirtschaft, Umwelt und Wasserwirtschaft, Wien, 2005.

[17] Kraus, D., Hübl, J. \& Rickenmann, D., Building vulnerability related to floods and debris flows - case studies, ed. Ammann W., Dannenmann, S. \& Vuillet, L., Risk21 - Coping with risks due to natural hazards in the $21^{\text {st }}$ century, London, pp. 181-190, 2006.

[18] Kranewitter, H., Liegenschaftsbewertung, Wien, 2002. 